Article

\title{
Fluorescent Silicate Materials for the Detection of Paraoxon
}

Brandy J. Johnson ${ }^{1}{ }^{1 *}$, Brian J. Melde ${ }^{1}$, Cassandra Thomas ${ }^{1}$, Anthony P. Malanoski ${ }^{1}$, Iwona A. Leska ${ }^{2}$, Paul T. Charles ${ }^{1}$, Damon A. Parrish ${ }^{1}$ and Jeffrey R. Deschamps ${ }^{1}$

1 Center for Bio/Molecular Science and Engineering, Naval Research Laboratory, Washington, DC 20375, USA; E-Mails: brian.melde@nrl.navy.mil (B.J.M.); cassandrathomas06@yahoo.com (C.T.); anthony.malanoski@nrl.navy.mil (A.P.M.); paul.charles@nrl.navy.mil (P.T.C.); damon.parrish@nrl.navy.mil (D.A.P.); jeff.deschamps@nrl.navy.mil (J.R.D.)

2 NOVA Research Incorporated, Alexandria, VA 22308, USA; E-Mail: iwona.leska.ctr@nrl.navy.mil

* Author to whom correspondence should be addressed; E-Mail: brandy.white@nrl.navy.mil; Tel.: +1-202-404-6100; Fax: +1-202-767-9598.

Received: 4 January 2010; in revised form: 2 March 2010 / Accepted: 8 March 2010 / Published: 19 March 2010

\begin{abstract}
Porphyrins are a family of highly conjugated molecules that strongly absorb visible light and fluoresce intensely. These molecules are sensitive to changes in their immediate environment and have been widely described for optical detection applications. Surfactant-templated organosilicate materials have been described for the semi-selective adsorption of small molecule contaminants. These structures offer high surface areas and large pore volumes within an organized framework. The organic bridging groups in the materials can be altered to provide varied binding characteristics. This effort seeks to utilize the tunable binding selectivity, high surface area, and low materials density of these highly ordered pore networks and to combine them with the unique spectrophotometric properties of porphyrins. In the porphyrin-embedded materials (PEMs), the organosilicate scaffold stabilizes the porphyrin and facilitates optimal orientation of porphyrin and target. The materials can be stored under ambient conditions and offer exceptional shelf-life. Here, we report on the design of PEMs with specificity for organophosphates and compounds of similar structure.
\end{abstract}

Keywords: mesoporous; organosilica; fluorescence; porphyrin; hierarchical; detection; organophosphate 


\section{Introduction}

Fluorescence-based detection of low molecular weight compounds can be accomplished using indicators of widely varying selectivity. Antibody-based recognition, for example, may offer highly selective binding of a single analyte. Other approaches may use a "fingerprint" response pattern across a number of indicators of lower selectivity. The effort described here employs a porphyrin for detection of targets. Porphyrins can be designed to offer semi-selective binding characteristics through altering the peripheral substituent groups of the compounds or through incorporation of a metal via coordination to the central nitrogen atoms. They have been employed for detection of a number of analytes from oxygen [1] to DNA [2]. Here, we do not seek to offer a review of these numerous efforts, instead we refer the reader to reviews of the topic [3,4]. The unique spectrophotometric characteristics of porphyrins result from their highly conjugated, macrocyclic structure (Figure 1). This structure yields large extinction coefficients especially in the blue region of the absorbance spectrum. The prominent electronic transitions of porphyrins and their metal complexes are the $\pi \rightarrow \pi^{*}$ transitions associated with the macrocycle. Several studies have shown that cyclic compounds bind cofacially to this macrocycle [5] even when the compound bears a nitrogen [6] or the porphyrin bears a metal [7].

Figure 1. Structures of the porphyrin parent compound and those porphyrins used in the presented studies; from left to right: porphine, meso-tetra(4-carboxyphenyl) porphine $\left(\mathrm{C}_{4} \mathrm{TPP}\right)$; 5-mono(4-carboxyphenyl)-10, 15, 20-triphenyl porphine $\left(\mathrm{C}_{1} \mathrm{TPP}\right)$; meso-tri(4sulfonatophenyl)mono(4-carboxyphenyl) porphine $\left(\mathrm{C}_{1} \mathrm{~S}_{3} \mathrm{TPP}\right)$; and Deuteroporphyrin IX 2,4 bis-ethylene glycol (DIXEG).
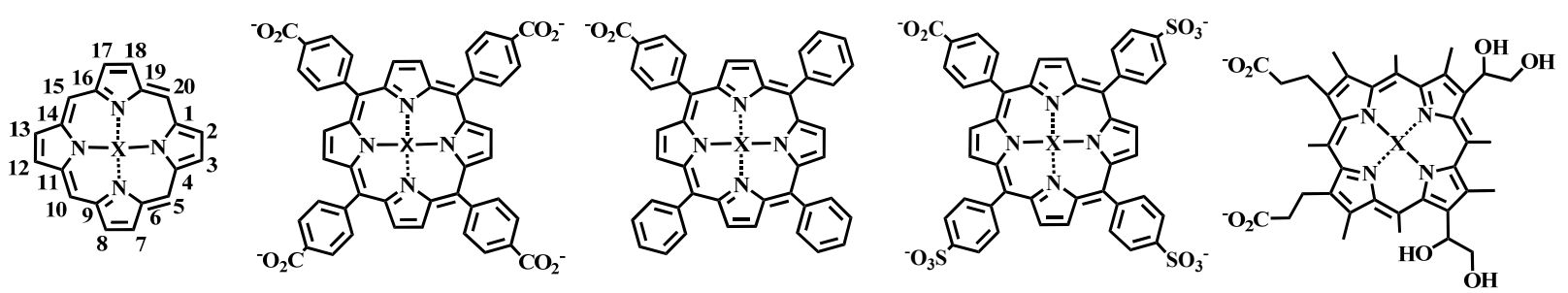

The semi-selective nature of porphyrin-based detection can impede the applicability of detection protocols to real-world scenarios. False-positive detection events can be reduced through careful selection of the porphyrin component so that detection relies on a shift (a peak/trough pair) in absorbance or fluorescence as opposed to a quench at a single wavelength. In order to further eliminate non-specific responses by the porphyrins, they can be used in conjunction with a scaffold that offers increased selectivity and protection of the indicators from irrelevant changes in the sensing environment. Porous silicate and organosilicate materials can be used to provide this protection. There are several reports of the use of mesoporous silicates as supports for porphyrin probes [8-18]. The International Union of Pure and Applied Chemistry (IUPAC) defines the prefix meso- as referring to a region 2 to $50 \mathrm{~nm}$; macro- is a region $>50 \mathrm{~nm}$; and micro- is a region $<2 \mathrm{~nm}$. Mesopores limit the analytes that are admitted to the interior of the material and pore size can be controlled to provide the possibility of molecular sieving. Mesoporosity can also be used to provide a high surface area (potentially exceeding $1,000 \mathrm{~m}^{2} / \mathrm{g}$ ) and pore volumes greater than $1 \mathrm{~cm}^{3} / \mathrm{g}$. These materials 
characteristics offer the ability to immobilize a high concentration of indicators in a small area, thereby increasing the overall binding affinity of the construct. Organosilicate materials have been used to adsorb targets in aqueous solution as well as target vapors [19-21].

The study presented here employed materials synthesized using a surfactant template approach for engineering porosity and organization on the meso-scale (Figure 2) [22-24]. In addition, polymerization (condensation)-induced phase separation has been used to produce macroporous frameworks which contain the ordered mesoporous structures [25-32]. The macroporous networks are intended to provide enhanced diffusion of targets within the materials and full access to the available surface area. The precursors used for materials synthesis consist of an organic moiety between two trialkoxysilane groups. The result is alternating siloxane and organic moieties in the pore walls of the materials that provide properties associated with both organic and inorganic materials [33,34]. The siloxane groups provide structural rigidity and hydrophilic character as well as the rugged character of a silicate material. The organic bridging groups provide binding characteristics normally associated with organic polymers. Through control of parameters during synthesis (precursors, surfactants, acids, etc.), both the structural and chemical properties of the materials can be tuned for a given application.

Figure 2. Synthesis of hierarchical macro/mesoporous organosilicate scaffolds.

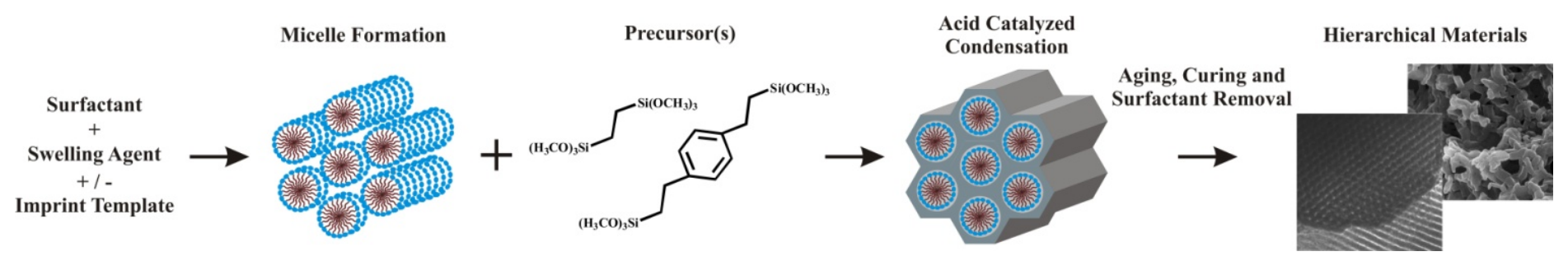

Adsorption of specific targets depends on the interaction of analytes with the surfaces of the porous materials. In these silicate materials, a type of molecular imprinting can be employed to provide areas on the surface of the materials which offer more favorable binding interactions. The process involves the introduction of a surfactant with a head-group structure similar to that of the target $[18,35,36]$. This target-like surfactant is incorporated as a fraction of the total surfactant in micelles around which the precursor materials are condensed. Upon extraction of the surfactant, sites that offer target complementary interactions remain in locations where the target-like surfactant was present. This approach has been shown to yield an increase in adsorption capacity and to increase the selectivity for a given target [35].

We have previously reported our efforts at combining the materials characteristics provided by organosilicate scaffolds with the optical and catalytic properties of porphyrins $[18,36]$. These efforts focused on nitroenergetic targets and achieved marginal success. In order to enhance the performance of the porphyrin-embedded materials (PEMs), the porous materials and the porphyrins used as well as the method of porphyrin incorporation into the scaffolds needed to be optimized. We recently reported on our efforts to optimize the structural characteristics of the materials [35]. Here, we describe the material characteristics developed for optimal paraoxon sorption, selection of porphyrin candidates, and the methods necessary for incorporation of functional porphyrin indicators into the materials. We also present results related to application of the constructs to detection of paraoxon. 


\section{Results and Discussion}

The targets of interest to this study are organophosphates, organophosphonates, and those compounds of related structure such as the nerve agents sarin and VX. For the worked presented here, paraoxon has been used as a model compound. The design of a PEM for detection begins with the selection of organic bridging groups that will provide affinity for the target. Synthesis conditions must be established, surfactants and imprint templates selected, and surface modification addressed in order to complete the organosilicate scaffold. The porphyrin component must also be selected and a suitable method for incorporation of the fluorophore into the scaffold determined. The porphyrin should provide binding affinity for the target as well as strong changes in spectrophotometric characteristics upon target interaction. In general, optimization of scaffold and porphyrin components is completed in parallel. Once the necessary components have been developed, methods for porphyrin incorporation are evaluated and final modifications are made to optimize the complete construct.

\subsection{Porphyrin Indicator}

A number of metalloporphyrin variants were considered for their potential as indicators of the presence of paraoxon. Four porphyrin structures (Figure 1) were combined with 21 metals to provide a total of 84 candidates. A rapid screening process was applied to the 84 candidate porphyrins in which the changes in the absorbance spectrum for a single porphyrin and target concentration were evaluated. The interaction of a target with a porphyrin in solution results in a change in the $\pi$-bond conformation of the porphyrin macrocycle and yields spectrophotometric characteristics that are different from those of the porphyrin free in solution. In an absorbance spectrum, these changes can include increased or decreased absorbance at one or many wavelengths. In order to analyze these changes, it is useful to employ an absorbance difference spectrum calculated as the point-by-point subtraction of the preexposure spectrum from the post-exposure spectrum. Examples of pre- and post-exposure spectra as well as a difference spectrum are provided in Figure 3. Here, Ni(II) $\mathrm{C}_{1} \mathrm{~S}_{3} \mathrm{TPP}(20 \mu \mathrm{M})$ was exposed to paraoxon (100 ppm). In the difference spectrum, the distance between the peak and the trough and the change in intensity (peak intensity minus the trough intensity) provide an indication of the binding affinity between the target and the porphyrin as well as the potential for application of the porphyrin as an indicator (sensitivity) [7]. Table 1 provides some examples of selected and rejected candidates. Selected candidates were those found to yield the largest $\Delta \lambda$ values, $\Delta \mathrm{I}$ values, or both. $\mathrm{Ni}$ (II) $\mathrm{C}_{1} \mathrm{~S}_{3} \mathrm{TPP}$ demonstrated the most significant change in wavelength while $\mathrm{Cu}(\mathrm{II}) \mathrm{C}_{4} \mathrm{TPP}$ showed the most significant change in intensity.

Candidates selected using the rapid screening method described above were further screened through the generation of a binding isotherm using a fixed porphyrin concentration and a range of target concentrations (Figure 3). Here, changes in intensity for a given wavelength are plotted as a function of the target concentration. This data can be used to determine binding constants $\left(\mathrm{K}_{11}\right)$ and changes in the extinction coefficients $\left(\Delta \varepsilon_{11}\right)$ upon binding (Table 1) [37]. On the basis of these results, $\mathrm{Ni}(\mathrm{II}) \mathrm{C}_{1} \mathrm{~S}_{3} \mathrm{TPP}, \mathrm{Ni}(\mathrm{II}) \mathrm{C}_{4} \mathrm{TPP}, \mathrm{Ni}(\mathrm{II}) \mathrm{C}_{1} \mathrm{TPP}, \mathrm{Fe}$ (II) $\mathrm{C}_{4} \mathrm{TPP}$, and $\mathrm{Cu}$ (II) $\mathrm{C}_{4} \mathrm{TPP}$ were selected for incorporation into the organosilicate scaffolds. The metal free versions of these porphyrins were also evaluated to further validate the selection process. 
Table 1. Interaction of porphyrins with paraoxon in solution.

\begin{tabular}{|c|c|c|c|c|c|}
\hline Porphyrin & $\Delta \lambda$ & $\Delta I$ & $\begin{array}{c}\mathrm{K}_{11} \\
(1 / \mathrm{mM})\end{array}$ & $\begin{array}{c}\Delta \varepsilon_{11} \text { Peak } \\
(\mathbf{A} / \mathbf{m M})\end{array}$ & $\begin{array}{c}\Delta \varepsilon_{11} \text { Trough } \\
(\mathrm{A} / \mathrm{mM})\end{array}$ \\
\hline \multicolumn{6}{|l|}{ Selected Candidates } \\
\hline $\mathrm{Ni}(\mathrm{II}) \mathrm{C}_{1} \mathrm{~S}_{3} \mathrm{TPP}$ & 19 & 0.010 & 0.66 & 57 & 4.3 \\
\hline $\mathrm{Fe}(\mathrm{II}) \mathrm{C}_{4} \mathrm{TPP}$ & 12 & 0.010 & 0.97 & 160 & 19 \\
\hline $\mathrm{Ni}(\mathrm{II}) \mathrm{C}_{4} \mathrm{TPP}$ & 11 & 0.006 & 3.1 & 43 & 11 \\
\hline $\mathrm{Cu}(\mathrm{II}) \mathrm{C}_{4} \mathrm{TPP}$ & 14 & 0.019 & 3.1 & 120 & 38 \\
\hline $\mathrm{Ni}(\mathrm{II}) \mathrm{C}_{1} \mathrm{TPP}$ & N/A & 0.432 & 4.1 & N/A & 220 \\
\hline \multicolumn{6}{|l|}{ Rejected Candidates } \\
\hline $\mathrm{Co}(\mathrm{II}) \mathrm{C}_{1} \mathrm{TPP}$ & $\mathrm{N} / \mathrm{A}$ & 0.012 & 0.22 & N/A & 3.0 \\
\hline $\mathrm{Fe}(\mathrm{II}) \mathrm{C}_{1} \mathrm{~S}_{3} \mathrm{TPP}$ & 10 & 0.010 & 0.09 & 14 & 36 \\
\hline $\mathrm{Pt}(\mathrm{IV}) \mathrm{C}_{4} \mathrm{TPP}$ & 8 & 0.002 & 0.06 & 5 & 63 \\
\hline
\end{tabular}

Figure 3. Changes in the porphyrin absorbance characteristics upon interaction with paraoxon. Panel A, absorbance spectra of Ni(II) $\mathrm{C}_{1} \mathrm{~S}_{3}$ TPP $(20 \mu \mathrm{M})$ in the absence and presence of paraoxon $(100 \mathrm{ppm})$ in $10 \mathrm{mM}$ PBS. Panel B, difference spectrum calculated as post-exposure minus pre-exposure absorbance. In this spectrum, the distance between the peak position and the trough position is $\Delta \lambda$ while the difference between the peak height and the trough depth is $\Delta \mathrm{I}$. Panel $\mathrm{C}$, concentration dependence of the interaction between paraoxon and $\mathrm{Cu}(\mathrm{II}) \mathrm{C}_{4} \mathrm{TPP}(4 \mu \mathrm{M})$.
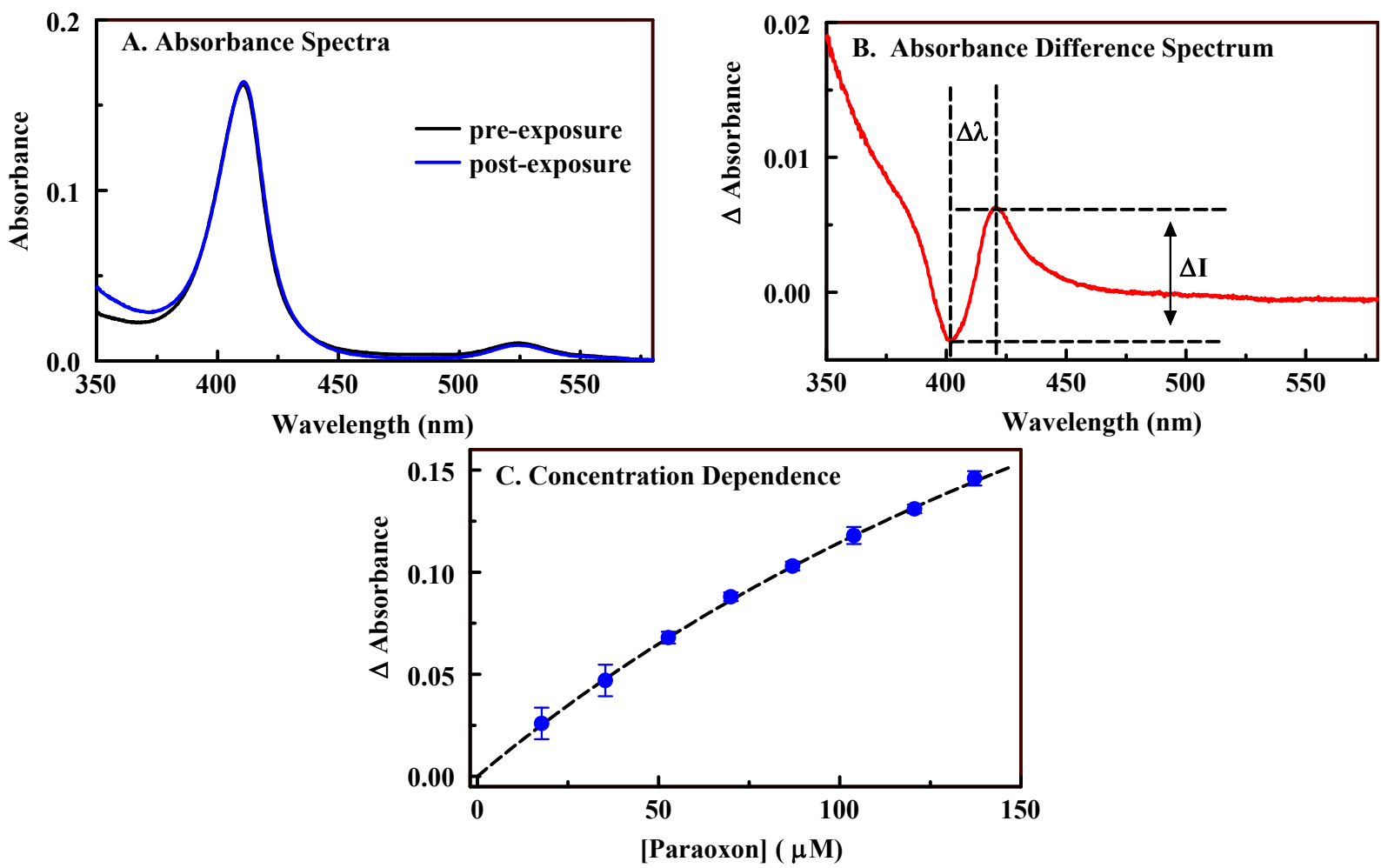

\subsection{The Organosilicate Scaffold}

Based on previous work [38], diethylbenzene (DEB) bridging groups were selected to provide binding affinity and capacity for paraoxon. Two materials were synthesized in order to compare 
imprinted and non-imprinted material variants (Figure 4). Both materials demonstrated Type IV nitrogen sorption isotherms and possessed narrow pore size distributions. XRD spectra displayed a peak in the low angle region near $0.96^{\circ} 2 \theta$ which could be attributed to the $(100)$ reflection common for mesoporous materials with hexagonal order. Higher order reflections of extremely low intensity were observed. Transmission electron microscopy of previously reported materials showed hexagonal arrays of parallel pore channels [25]. The first material (Material 1) was a co-condensate of 50\% DEB and 1,2-bis(trimethoxysilyl)ethane (BTE). The inclusion of ethane bridges in co-condensates can yield enhanced structural characteristics and improves the effectiveness of the imprinting process used in the second material (Table 2) [35]. The process of imprinting the organosilicate materials involves the use of a surfactant with a modified head group. Here, esterification of Pluronic P123 using diethyl chlorophosphate (Figure 5) produces an analog of the phosphoric acid portion of the paraoxon structure. The goal of this process is to generate sites possessing more favorable interaction characteristics on the pore walls. The modified surfactant was included as $12.6 \%$ of the total surfactant used during synthesis of Material 2. Conditions for synthesis, including concentrations of surfactant, acid, and swelling agent, were selected based on previous work [25].

Figure 4. Structural characterization (Material 1, red; Material 2, blue; Material 5, black). Panel A, nitrogen sorption isotherms offset by 0,150 , and $350 \mathrm{~cm}^{3} / \mathrm{g}$, respectively. Panel B, pore size distributions. Panel C, XRD spectra (inset shows expansion of the 1.5 to 4 range).
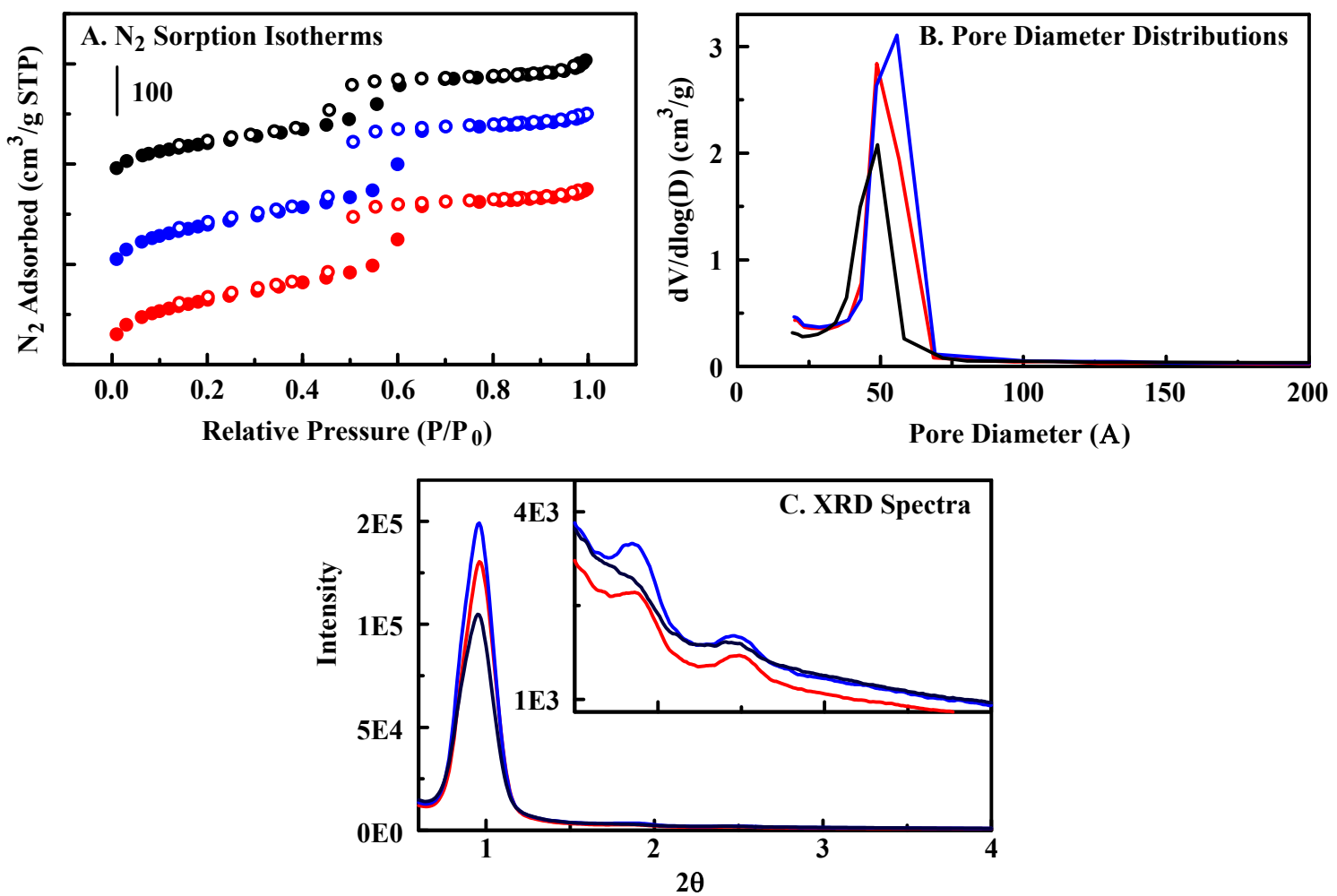
Table 2. Material Characteristics.

\begin{tabular}{|c|c|c|c|c|}
\hline Material & Designation & $\begin{array}{l}\text { BET Surface } \\
\text { Area }\left(\mathrm{m}^{2} / \mathrm{g}\right)\end{array}$ & $\begin{array}{c}\text { BJH Pore } \\
\text { Volume }\left(\mathrm{cm}^{3} / \mathrm{g}\right) \\
\end{array}$ & $\begin{array}{l}\text { Average Pore } \\
\text { Diameter }(\AA)\end{array}$ \\
\hline 50:50 DEB:BTE No Imprint & Material 1 & 445 & 0.476 & 49 \\
\hline 50:50 DEB:BTE Imprinted & Material 2 & 478 & 0.527 & 56 \\
\hline $100 \%$ DEB $^{*}$ & -- & 455 & 0.414 & 45 \\
\hline $100 \%$ BTE* & -- & 800 & $>1$ & 75 \\
\hline $\begin{array}{l}\text { 50:50 DEB:BTE No Imprint } \\
\text { with amine functionality }\end{array}$ & Material 3 & 648 & 0.587 & 49 \\
\hline $\begin{array}{l}\text { 50:50 DEB:BTE Imprinted with } \\
\text { amine functionality }\end{array}$ & Material 4 & 405 & 0.443 & 48 \\
\hline $\begin{array}{l}\text { 50:50 DEB:BTE Imprinted with } \\
\text { high amine functionality }\end{array}$ & Material 5 & 343 & 0.374 & 49 \\
\hline
\end{tabular}

* $100 \%$ DEB and 100\% BTE material characteristics are provided for comparison purposes [25].

Figure 5. Esterification of the surfactant (A) to provide an analog of the paraoxon structure (B).

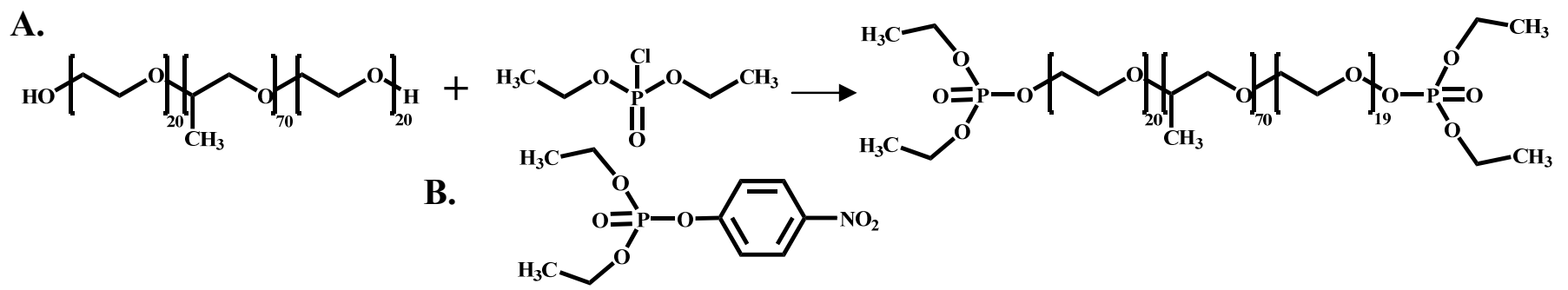

Binding of paraoxon from aqueous solution by the organosilicate materials was evaluated to determine the binding capacity and target affinity provided by the scaffold. An HPLC difference method was applied in which the concentration of target in the sample is measured before and after exposure to the sorbent. The goal is for the scaffold to provide a locally high concentration of target in the vicinity of the porphyrin indicator. This should enhance the sensitivity of detection. We have previously shown that imprinting of the organosilicate materials enhances selective or semi-selective adsorption of analytes [18]. This effect should reduce the interaction of the porphyrin indicators with non-target compounds. Binding isotherms for Materials $\mathbf{1}$ and $\mathbf{2}$ are presented in Figure 6. Application of the imprinting process slightly increased the target bound by the material. Typically, the LangmuirFreundlich model, a variant of the Langmuir model used to account for surface heterogeneity $[39,40]$, is applied to these binding isotherms. In this case, the amount of target bound by the material is clearly in excess of that expected for single layer adsorption. Single layer adsorption is an assumption necessary to the typical model. Binding of $300 \mathrm{mg}$ paraoxon per gram sorbent would be sufficient to fill nearly half of the available mesopore volume (based on $\mathrm{N}_{2}$ sorption). This binding capacity was far greater than expected. An effort is underway to understand this phenomenon, but those studies are beyond the scope of this manuscript. 
Figure 6. Paraoxon binding isotherms for imprinted (Material 2, red) and non-imprinted (Material 1, blue) organosilicate scaffolds.

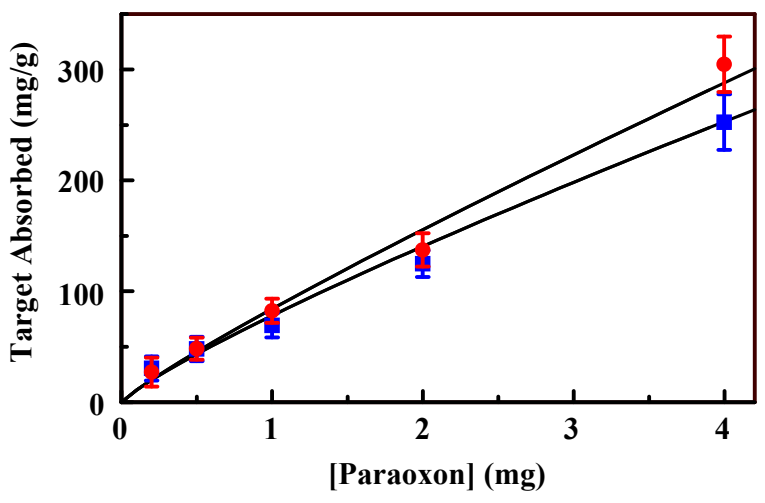

\subsection{The Fluorescent Construct}

Porphyrins $\left(\mathrm{C}_{1} \mathrm{~S}_{3} \mathrm{TPP}, \mathrm{C}_{4} \mathrm{TPP}\right.$, and $\left.\mathrm{C}_{1} \mathrm{TPP}\right)$ were incorporated into both imprinted and nonimprinted organosilicate scaffolds (Materials 3 and 4) using EDC chemistry. Metalloporphyrin variants of the materials were generated by refluxing the porphyrin-embedded organosilicate in solutions of metals. These materials were synthesized with a low level of amine functionality in an attempt to preserve the binding characteristics of the organosilicate scaffold. In addition, excessively high loading of porphyrins onto a solid surface can result in co-facial stacking of the macrocycles. This type of stacking will significantly alter the spectrophotometric characteristics of the porphyrins as well as the response of the indicators to a target. The fluorescence response of the constructs to varying concentrations of paraoxon was evaluated in a manner similar to that described above (Section 2.1). Pre- and post-exposure fluorescence spectra were collected (Figure 7), and the difference spectra calculated. $\mathrm{Ni}$ (II) complexes of $\mathrm{C}_{1} \mathrm{~S}_{3} \mathrm{TPP}, \mathrm{C}_{4} \mathrm{TPP}$, and $\mathrm{C}_{1} \mathrm{TPP}$ as well as $\mathrm{Cu}$ (II) and $\mathrm{Fe}$ (II) complexes of $\mathrm{C}_{4}$ TPP were evaluated. $\mathrm{Ni}(\mathrm{II}) \mathrm{C}_{1} \mathrm{~S}_{3} \mathrm{TPP}$ showed the highest sensitivity with the response in the imprinted material being enhanced over that of the non-imprinted material. A detection limit of $3 \mathrm{ppm}$ was obtained for the $\mathrm{Ni}$ (II) $\mathrm{C}_{1} \mathrm{~S}_{3}$ TPP-embedded version of Material 4. All porphyrin-embedded versions of Material 3 showed smaller changes in intensity than their Material 4 counter parts. The limit of detection (LOD) for paraoxon using Ni(II) $\mathrm{C}_{4}$ TPP was 50 ppm in Material 3 versus 10 ppm in Material 4. $\mathrm{Fe}$ (II) $\mathrm{C}_{4}$ TPP showed dose dependence in the imprinted material but was not as sensitive as the $\mathrm{Ni}$ (II) $\mathrm{C}_{1} \mathrm{~S}_{3}$ TPP imprinted material. The $\mathrm{Cu}$ (II) $\mathrm{C}_{4}$ TPP imprinted material showed dose dependence but with small changes in fluorescence. Limits of detection (LODs) and characteristic interaction wavelengths for several of these materials are provided in Table 3.

Given the high binding capacity of the scaffold for paraoxon, the high detection limit obtained with the PEMs $(>3 \mathrm{ppm})$ tended to indicate the need for increased porphyrin loading in the construct. Because incorporation of high concentrations of 3-aminopropyltrimethoxysilane (APS) during synthesis causes disruption of the material structure, a grafting approach was used to increase the porphyrin loading level. Material 5 is the result of post-synthesis grafting of APS onto Material 2. Using this approach, higher amine loading levels can be achieved, and the amine groups will be on the scaffold surfaces as opposed to also being distributed within the solid portion of the scaffold. UV/vis 
analysis of the porphyrin concentration remaining in solution following the immobilization reaction indicates loading of 3.0 weight percent porphyrin in Material 5. The porphyrin loading level in Material 4 was approximately 0.5 weight percent.

Figure 7. Interaction of paraoxon with Material 4. Panel A, fluorescence excitation spectra for the $\mathrm{Ni}$ (II) $\mathrm{C}_{1} \mathrm{~S}_{3}$ TPP-embedded version of Material 4 in the presence/absence (red) of 5 ppm (blue) and 100 ppm (black) paraoxon. Panel B, difference fluorescence spectra for exposure of the material to $0.1 \mathrm{ppm}$ (green), $10 \mathrm{ppm}$ (blue), and $100 \mathrm{ppm}$ (black). Panel C, binding isotherm for the interaction based on the peak/trough difference in intensity at 435 and $495 \mathrm{~nm}$.
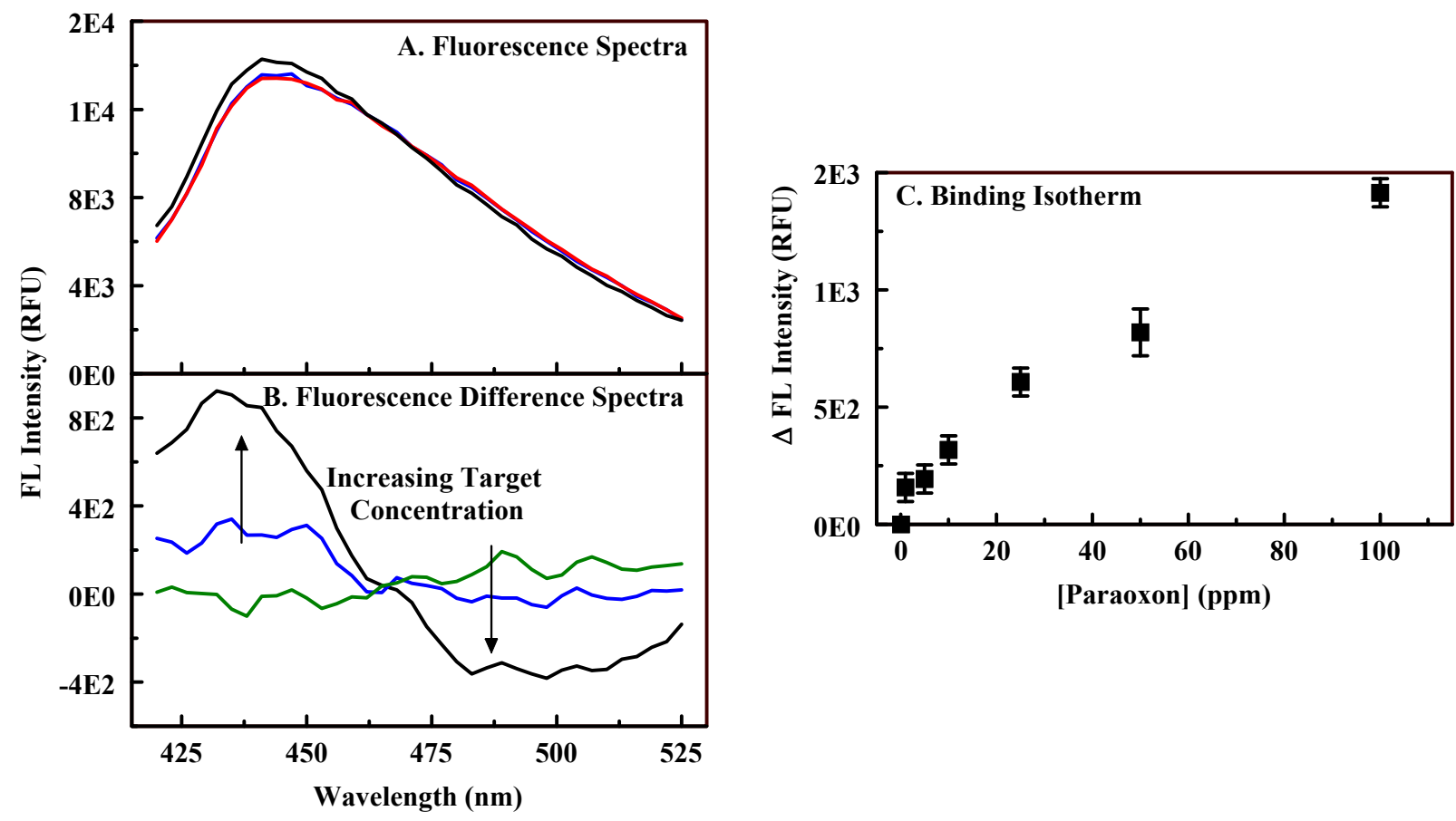

The fluorescence responses to paraoxon exposure of porphyrin-embedded versions of Material $\mathbf{5}$ were evaluated. As shown in Figure 8, the change in intensity for a given exposure level is enhanced as a result of the increased porphyrin concentration (compare to Figure 7). This is expected as the change in absorbance/fluorescence is dependent on both analyte and target concentration [37]. The binding isotherms for the PEM materials (high and low amine loading) do not provide linear BenesiHilderbrand plots and, therefore, are not well represented by standard binding models typically applied to porphyrin-target interactions. Examples of target binding isotherms are provided in Figures 7 and 8 . This deviation from standard models is not unexpected as both the affinity of the porphyrin and that of the scaffold contribute to the effective environment of the porphyrin indicators. Though a model for the binding interaction is not available, it is clear that increasing the porphyrin loading within the scaffolds provides enhanced target detection. The limit of detection for paraoxon using $\mathrm{Ni}$ (II) $\mathrm{C}_{1} \mathrm{~S}_{3} \mathrm{TPP}$ in Material 5 (50 ppb) was significantly better than that for the porphyrin in Material 4 (3 ppm). Based on the experimental protocols used, experiments with Material 5 contained approximately $30 \mu \mathrm{g}$ porphyrin while those with Material 4 contained only $5 \mu \mathrm{g}$ for the same mass of PEM powder. Experiments in solution using $\mathrm{Ni}(\mathrm{II}) \mathrm{C}_{1} \mathrm{~S}_{3} \mathrm{TPP}$ utilized $17 \mu \mathrm{g}$ porphyrin and achieved a detection limit 
of $15 \mathrm{ppm}$. These differences in porphyrin concentration are not sufficient to fully account for the reduced detection limits noted with the PEM materials. This discrepancy implicates a contribution by the altered environment provided by the PEM.

Table 3. Interaction of porphyrin embedded materials with paraoxon. Peak and trough positions are taken from difference excitation spectra. Limits of detection are based on the concentration required to yield a $\Delta \mathrm{I}$ of three times the noise in the measurement.

\begin{tabular}{|c|c|c|c|c|}
\hline \multirow{2}{*}{ Scaffold } & Porphyrin & Peak (nm) & $\begin{array}{c}\text { Trough } \\
\text { (nm) }\end{array}$ & $\begin{array}{c}\text { LOD } \\
\text { (ppm) }\end{array}$ \\
\hline \multirow{2}{*}{ Material 3 } & $\mathrm{Fe}(\mathrm{II}) \mathrm{C}_{4} \mathrm{TPP}$ & 430 & 410 & 90 \\
\cline { 2 - 5 } & $\mathrm{Ni}(\mathrm{II}) \mathrm{C}_{4} \mathrm{TPP}$ & 416 & 438 & 50 \\
\cline { 2 - 5 } & $\mathrm{Ni}(\mathrm{II}) \mathrm{C}_{1} \mathrm{TPP}$ & $\mathrm{N} / \mathrm{A}$ & $\mathrm{N} / \mathrm{A}$ & $\mathrm{N} / \mathrm{A}^{*}$ \\
\hline \multirow{4}{*}{ Material 4 } & $\mathrm{Ni}(\mathrm{II}) \mathrm{C}_{1} \mathrm{~S}_{3} \mathrm{TPP}$ & 495 & 435 & 3 \\
\cline { 2 - 5 } & $\mathrm{Ni}(\mathrm{II}) \mathrm{C}_{1} \mathrm{TPP}$ & 420 & 412 & 50 \\
\cline { 2 - 5 } & $\mathrm{Ni}(\mathrm{II}) \mathrm{C}_{4} \mathrm{TPP}$ & 417 & 433 & 10 \\
\hline \multirow{2}{*}{ Material 5 } & $\mathrm{Ni}(\mathrm{II}) \mathrm{C}_{1} \mathrm{~S}_{3} \mathrm{TPP}$ & 414 & 430 & 0.05 \\
\cline { 2 - 5 } & $\mathrm{Ni}(\mathrm{II}) \mathrm{C}_{1} \mathrm{TPP}$ & 424 & 414 & 8 \\
\cline { 2 - 5 } & $\mathrm{C}_{4} \mathrm{TPP}$ & 420 & $\mathrm{~N} / \mathrm{A}$ & 50 \\
\hline
\end{tabular}

* No change in fluorescence was observed for the measured range of concentrations, $0.1 \mathrm{ppm}$ to $100 \mathrm{ppm}$.

Table 3 provides interaction wavelengths and limits of detection for the best performing PEMs as well as data sets that allow comparison of the performance of the different scaffolds. The characteristic wavelengths for the interaction of a given porphyrin with paraoxon were found to differ in several cases dependent upon the state of the porphyrin, ie., whether in solution or in a particular material. The interaction wavelengths for porphyrins embedded in Materials 3 and $\mathbf{4}$ were similar to each other but not to those observed in solution. The interaction wavelengths for porphyrins embedded in Material 5 differed from both the other materials and those of solution. For example, the characteristic interaction wavelengths for $\mathrm{Ni}(\mathrm{II}) \mathrm{C}_{1} \mathrm{~S}_{3}$ TPP in solution were at 402 and $408 \mathrm{~nm}$; in Material 4, they were 495 and $435 \mathrm{~nm}$; in Material 5, they were 414 and $430 \mathrm{~nm}$. These differences are likely a result of variations in the environment of the porphyrins. When the excitation fluorescence spectra of the porphyrin in the various environments are compared, specific differences are noted. In solution the spectrum consists of a single, well defined peak centered at $412 \mathrm{~nm}$ (the Soret, Figure 3) and several less intense bands at longer wavelengths. When embedded in Materials 3 and 4, the Soret is broadened and red-shifted to $444 \mathrm{~nm}$ (Figure 7). While a red-shift is consistent with the formation of porphyrin aggregates, the concentration of porphyrin in this material is well below the level that would be expected to cause stacking. These changes are more likely a result of the interaction of the porphyrin with the scaffold, perhaps the $\pi$-bonds of the diethylbenzene bridging groups. The porphyrin embedded in Material $\mathbf{5}$ has very different spectrophotometric characteristics. The Soret is centered around $424 \mathrm{~nm}$, but there is an additional band at $515 \mathrm{~nm}$. The intensity of the additional band is $60 \%$ of that for the band at $424 \mathrm{~nm}$ making it unlikely that this is a $\mathrm{Q}$ band for the porphyrin. Interaction between paraoxon and the porphyrin results in a change in absorbance related to the band at $424 \mathrm{~nm}$, but not the band at $515 \mathrm{~nm}$. The two bands are likely the result of porphyrin populations in two different environments. A portion of the embedded indicators see an environment that differs only slightly from the conditions 
experienced in solution $(424 \mathrm{~nm})$ while the other portion $(515 \mathrm{~nm})$ are either in an environment that is favorable to porphyrin stacking or to a strong interaction with the scaffold.

Figure 8. Interaction of paraoxon with Material 5. Panel A, fluorescence excitation spectrum of $\mathrm{Ni}(\mathrm{II}) \mathrm{C}_{1} \mathrm{~S}_{3}$ TPP-embedded Material 5. Compare to $\mathrm{Ni}(\mathrm{II}) \mathrm{C}_{1} \mathrm{~S}_{3}$ TPP-embedded Material 4 (see Figure 7). Panel B, fluorescence difference spectra for exposure of Ni(II) $\mathrm{C}_{1} \mathrm{~S}_{3}$ TPP-embedded Material 5 to 0.1 (black), 8 (blue), and 800 (red) ppm paraoxon. Panel $\mathrm{C}$, binding isotherm for $\mathrm{Ni}(\mathrm{II}) \mathrm{C}_{1} \mathrm{~S}_{3}$ TPP-embedded Material 5 (red) based on the peak/trough difference in intensity at 414 and $430 \mathrm{~nm}$; binding isotherms for $\mathrm{C}_{4} \mathrm{TPP}$ (black)- and Ni(II) $\mathrm{C}_{1}$ TPP (blue)-embedded versions of Material 5.
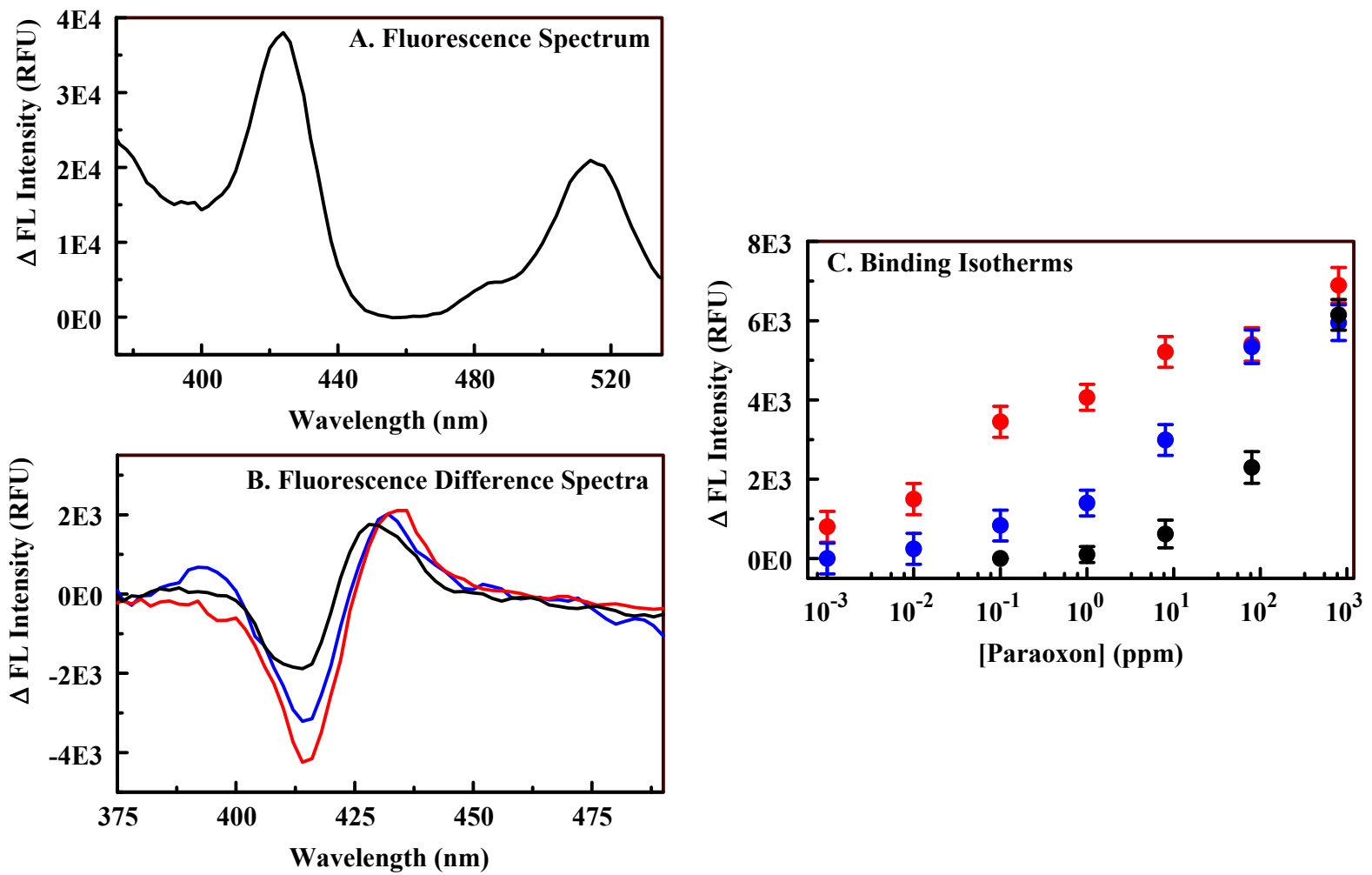

\section{Experimental Section}

Meso-tetra(4-carboxyphenyl) porphine ( $\left.\mathrm{C}_{4} \mathrm{TPP}\right)$; 5-mono(4-carboxyphenyl)-10, 15, 20-triphenyl porphine $\left(\mathrm{C}_{1} \mathrm{TPP}\right)$; meso-tri(4-sulfonatophenyl)mono(4-carboxyphenyl) porphine $\left(\mathrm{C}_{1} \mathrm{~S}_{3} \mathrm{TPP}\right)$; and Deuteroporphyrin IX 2,4 bis-ethylene glycol (DIXEG) were obtained from Frontier Scientific, Logan, UT. Bis(trimethoxysilylethyl)benzene (DEB), 3-aminopropyltrimethoxysilane (APS) and 1,2bis(trimethoxysilyl)ethane (BTE) were obtained from Gelest, Inc. (Tullytown, PA). Pluronic®P123 was generously donated by BASF. Diethyl chlorophosphate, dichloromethane $(\geq 99.5 \%)$, magnesium turnings (98\%), mesitylene (1,3,5-trimethylbenzene or TMB), and paraoxon were purchased from Sigma-Aldrich (St. Louis, MO). 1-Ethyl-3-[3-dimethylaminopropyl]carbodiimide (EDC) was purchased from Pierce Chemical Company (Rockford, IL). Chemicals were used as received. Water was deionized to $18.2 \mathrm{M} \Omega \mathrm{cm}$ using a Millipore Milli Q UV-Plus water purification system. 
The target analog used for imprinting was generated through esterification of Pluronic P123 (abbreviated P123 throughout) with diethyl chlorophosphate [41-43]. Briefly, P123 (4g; 0.7 mmol) and diethyl chlorophosphate $(0.4 \mathrm{~mL} ; 3 \mathrm{mmol})$ were dissolved in $60 \mathrm{~mL}$ of dichloromethane. Magnesium turnings were added and the mixture was refluxed for $3 \mathrm{~h}$. The liquid was shaken with $60 \mathrm{~mL} 2 \%$ $\mathrm{NaHCO}_{3}$ in a separatory funnel. The organic phase was then extracted and evaporated under vacuum.

Our preparation method for the materials using P123 in acidic media has been described elsewhere [25]. Briefly, $1.9 \mathrm{~g} \mathrm{P} 123$ (1.66 g P123 and $0.24 \mathrm{~g}$ imprint P123 for imprinted versions, Materials 2, 4, and 5) and 0.55 $\mathrm{g} \mathrm{TMB}$ were dissolved in $7.5 \mathrm{~g} 0.1 \mathrm{M} \mathrm{HNO}_{3}$ with stirring at $60{ }^{\circ} \mathrm{C}$. The stirring solution was allowed to cool to room temperature and a silane mixture consisting of 0.00784 mol total bis silane (BTE + DEB) was added drop-wise. The reaction mixture was stirred until homogeneous and then transferred to a culture tube which was sealed tightly and heated at $60{ }^{\circ} \mathrm{C}$ over night (approximately $18 \mathrm{~h}$ ). A white gel formed during this period. The tube was unsealed and heated at $60{ }^{\circ} \mathrm{C}$ for $2 \mathrm{~d}$, and then $80^{\circ} \mathrm{C}$ for $2 \mathrm{~d}$. The product in the form of a white monolith was refluxed three times in ethanol for at least $12 \mathrm{~h}$ to extract P123, a process that rendered the monolith a powder. The material was collected by suction filtration, rinsed with ethanol and water, and dried at $100{ }^{\circ} \mathrm{C}$.

Amine functional groups were directly incorporated in Materials 3 and 4 through inclusion of $0.05 \mathrm{~g}$ APS in the BTE-DEB silane mixture that was added drop-wise to the P123 solution. For Material 4, the acid concentration was adjusted to $9.5 \mathrm{~g} 0.1 \mathrm{M} \mathrm{HNO}_{3}$. Material 5 was synthesized with $0.6 \mathrm{~g} \mathrm{TMB}$

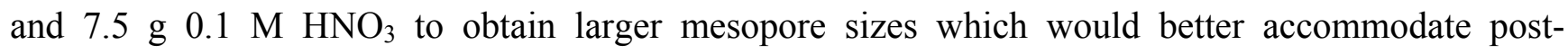
synthetic grafting of APS. Sorbent material $(1.0 \mathrm{~g})$ was dried at $110{ }^{\circ} \mathrm{C}$ and added to a solution of 1 $\mathrm{mL}$ APS in $100 \mathrm{~mL}$ toluene. The mixture was refluxed for $18 \mathrm{~h}$. Grafted material was collected by vacuum filtration, washed with toluene and excess ethanol, and dried at $100{ }^{\circ} \mathrm{C}$.

$\mathrm{N}_{2}$ sorption experiments were completed on a Micromeritics ASAP 2010 at $77 \mathrm{~K}$. Samples were degassed to $1 \mu \mathrm{m} \mathrm{Hg}$ at $100{ }^{\circ} \mathrm{C}$ prior to analysis. Surface area was determined by use of the BrunauerEmmett-Teller (BET) method; pore size was calculated by the Barrett-Joyner-Halenda (BJH) method from the adsorption branch of the isotherm; total pore volume was calculated by the single point method at relative pressure $\left(\mathrm{P} / \mathrm{P}_{0}\right)$ 0.97. Powder $\mathrm{x}$-ray diffraction patterns were collected at room temperature using $\mathrm{CuK} \alpha$ radiation from a Brüker MICROSTAR-H x-ray generator operated at $40 \mathrm{kV}$ and $30 \mathrm{~mA}$ equipped with a $3 \mathrm{mRadian}$ collimator, and a Brüker Platinum-135 CCD area detector. A custom fabricated beamstop was mounted on the detector to allow data collection to approximately $0.4^{\circ} 2 \theta$ (approximately $210 \AA$ ) with a sample to detector distance of $30 \mathrm{~cm}$. After unwarping the images the $\mathrm{XRD}^{2}$ plug-in was used to integrate the diffraction patterns from $0.5^{\circ}$ to $8.4^{\circ} 2 \theta$.

Metalloporphyrin solutions were prepared by mixing porphyrin solutions with concentrated metal solutions to achieve a 1:1 molar ratio. The solutions were then heated at $90{ }^{\circ} \mathrm{C}$ until dry. Metalloporphyrins were resuspended to a final concentration of $2 \mathrm{mM}$ in deionized water. Porphyrins were incorporated into the silicate materials through standard EDC chemistry. Silicate material $(0.5 \mathrm{~g})$ was added to a solution prepared using $9 \mathrm{mg}$ EDC and $15 \mathrm{mg}$ porphyrin in $100 \mathrm{mM}$ MES buffer $(40 \mathrm{~mL})$. The solution was incubated with agitation overnight and rinsed with $5 \mathrm{mM}$ sodium hydroxide, ethanol, and water. Metals were incorporated into the immobilized porphyrins using a reflux technique following incorporation into the scaffold. In all cases, a $1 \mathrm{mM}$ solution of metal in deionized water was used for this process $(300 \mathrm{~mL},<500 \mathrm{mg}$ sorbent $)$. 
Concentrations for analyte adsorption experiments are indicated in the text and figure captions. For HPLC analysis, solutions were filtered following incubation using $0.2 \mu \mathrm{m}$ PTFE syringe filters to remove the adsorbent and the captured target. The solution was then analyzed and the amount adsorbed was calculated via difference method. Standard curves were generated for each set of experiments to verify sample concentrations and proper instrument function. The HPLC method was adapted from Gebreegzi, et al. [44] and employed a Shimadzu High Performance Liquid Chromatography (HPLC) system with dual-plunger parallel flow solvent delivery modules (LC-20AD) and an auto-sampler (SIL-20AC; $20 \mu \mathrm{L}$ injection volume) coupled to a photodiode array detector (SPD-M20A; $277 \mathrm{~nm}$ detection). The stationary phase was a C18 stainless steel analytical column (Luna, $150 \mathrm{~mm} \times 4.6 \mathrm{~mm}, 3 \mu \mathrm{m}$ diameter; Phenomenex, Torrance, CA) with an isocratic 50:50 acetonitrile: $1 \%$ aqueous acetic acid mobile phase $(1.5 \mathrm{~mL} / \mathrm{min})$.

Fluorescence excitation (655 nm emission) and emission spectra (collected at the wavelength with greatest extinction coefficient for the given porphyrin) of the porphyrin-embedded materials were collected in 96-well format with a Tecan XSafire monochromator-based microplate reader $(1 \mathrm{~nm}$ resolution). Fluorescence spectra of the PEMs were collected for dry materials. Paraoxon exposure was accomplished by applying the target as a solution in acetonitrile and allowing the solvent to fully evaporate before collection of post-exposure fluorescence spectra. Controls were exposed to acetonitrile only (no target) to verify that this procedure did not impact the PEM spectra. Absorbance spectra of porphyrins in aqueous solution (10 $\mathrm{mM}$ phosphate buffered saline, PBS) were also collected using the plate reader $(370 \mathrm{~nm}-770 \mathrm{~nm}$ at $2 \mathrm{~nm}$ resolution). Difference spectra are calculated as the point-by-point subtraction of the pre-exposure spectrum from the post-exposure spectrum. Concentration dependence data presented is based on the average of measurements conducted in triplicate. Fitting of the data was accomplished in PSI-Plot v 8.51 (Poly Software International, Inc.).

\section{Conclusions}

We have described the development of porphyrin-embedded organosilicate materials for application to the detection of paraoxon and compounds of related structure. These materials are synthesized using an imprinting technique that has been shown to enhance both the binding capacity of the scaffold and the selectivity of the sorbents for targets of specific structure [18]. Porphyrin candidates were selected based on a rapid screening protocol in which the changes in intensity and wavelength shifts at a given porphyrin and target concentration are compared. Down-selection of candidates based on these criteria is followed by more detailed characterization for final indicator selection. We have shown here that this approach provides the information necessary for selection of appropriate porphyrin candidates. Incorporation of selected porphyrin indicators into the materials at low loading levels ( 0.5 weight percent) was found to provide constructs with poor sensitivity to paraoxon resulting in high limits of detection. Increasing porphyrin loading levels resulted in enhanced construct sensitivity and significantly lower limits of detection. The complex fluorescence spectra of these constructs indicated that only a portion of the indicator incorporated into the scaffold was utilized in detection of paraoxon.

Our previous efforts were aimed at designing PEMs for the detection and photocatalytic conversion of nitroenergetics $[18,36]$. As in the current study, those efforts sought to combine the semi-selective binding characteristics and rugged nature of organosilicate materials with the spectrophotometric 
characteristics of porphyrins. Those initial efforts were only marginally successful. Here, we have shown that tuning of the materials including adjustment of porphyrin incorporation methods provide enhanced construct characteristics. The methods developed for this study provided significant enhancement, but the procedure needs to be further optimized. The materials used in this study have been synthesized with an open macrostructure which facilitates rapid diffusion of targets throughout the scaffold. The open structure also provides enhanced access to the available surface area, access that is often restricted in purely meso- or microporous materials. The materials used here were synthesized as powders which are readily applicable to column and packed-bed formats. In these formats the open structure reduces the back pressures typically encountered when using purely meso- or microporous materials.

\section{Acknowledgements}

C. Thomas participated in this effort as part of a National Science Foundation (NSF) sponsored NRL HBCU/MI/TCU summer internship. We have applied the SDC approach ("sequence-determinescredit”) for determining the sequence of authors [45]. This research was sponsored by the U.S. Naval Research Laboratory (NRL 6.1 WU\#69-8765), U.S. DoD Strategic Environmental Research and Development Program (SERDP; ER-1604), and the U.S. Defense Threat Reduction Agency (DTRA; BA08PRO015). The views expressed here are those of the authors and do not represent those of the U.S. Navy, the U.S. Department of Defense, or the U.S. Government.

\section{References and Notes}

1. Amao, Y. Probes and Polymers for Optical Sensing of Oxygen. Microchim. Acta 2003, 143, 1-12.

2. Feng, Y.; Pilbrow, J.R. Porphyrin Intercalation and Non-specific 'Edge on' Outside Binding to Natural DNA. Biophys. Chem. 1990, 36, 117-131.

3. Malinski, T. Applications: Past, Present, Future. In The Porphyrin Handbook, 1st ed.; Kadish, K. M., Smith, K.M., Guilard, R., Eds.; Academic Press: New York, NY, USA, 2000; Volume 6, p. 231.

4. Ogoshi, H.; Mizutani, T.; Hayashi, T.; Kuroda, Y., Porphyris and Metalloporphyrins as Receptor Models in Molecular Recognition. In The Porphyrin Handbook; Kadish, K.M., Smith, K.M., Guilard, R., Eds.; Academic Press: New York, NY, USA, 2000; Volume 6, p. 279.

5. Mauzerall, D. Spectra of Molecular Complexes of Porphyrins in Aqueous Solution. Biochemistry 1965, 4, 1801-1810.

6. Shelnutt, J.A. Molecular Complexes of Copper Uroporphyrin with Aromatic Acceptors. J. Phys. Chem. 1983, 87, 605-616.

7. Schneider, H.-J.; Wang, M. Ligand-Porphyrin Complexes: Quantitative Evaluation of Stacking and Ionic Contributions. J. Org. Chem. 1994, 59, 7464-7472.

8. Balaji, T.; Sasidharan, M.; Matsunaga, H. Optical Sensor for the Visual Detection of Mercury Using Mesoporous Silica Anchoring Porphyrin Moiety. Analyst 2005, 130, 1162-1167.

9. Balaji, T.; El-Safty, S.A.; Matsunaga, H.; Hanaoka, T.; Mizukami, F. Optical Sensors Based on Nanostructured Cage Materials for the Detection of Toxic Metal Ions. Angew. Chem. Int. Ed. 2006, 45, 7202-7208. 
10. Han, B.-H.; Manners, I.; Winnik, M.A. Oxygen Sensors Based on Mesoporous Silica Particles on Layer-by-Layer Self-assembled Films. Chem. Mater. 2005, 17, 3160-3171.

11. Zhang, H.; Sun, Y.; Zhang, P.; Wang, Y. Oxygen Sensing Materials Based on Mesoporous Silica MCM-41 and Pt(II)-porphyrin Complexes. J. Mater. Chem. 2005, 15, 3181-3186.

12. Huo, C.; Zhang, H.; Zhang, H.; Zhang, H.; Yang, B.; Zhang, P.; Wang, Y. Synthesis and Assembly with Mesoporous Silica MCM-48 of Platinum(II) Porphyrin Complexes Bearing Carbazyl Groups: Spectroscopic and Oxygen Sensing Properties. Inorg. Chem. 2006, 45, 4735-4742.

13. Cardoso, W.S.; Francisco, M.S.P.; Landers, R.; Gushikem, Y. Co(II) porphyrin Adsorbed on $\mathrm{SiO}_{2} / \mathrm{SnO}_{2} /$ phosphate Prepared by the Sol-gel Method. Application in Electroreduction of Dissolved Dioxygen. Electrochim. Acta 2005, 50, 4378-4384.

14. Cardoso, W.S.; Gushikem, Y. Electrocatalytic Oxidation of Nitrite on a Carbon Paste Electrode Modified with $\mathrm{Co}$ (II) Porphyrin Adsorbed on $\mathrm{SiO}_{2} / \mathrm{SnO}_{2} /$ Phosphate Prepared by the Sol-gel Method. J. Electroanal. Chem. 2005, 583, 300-306.

15. Tao, S.; Li, G. Porphyrin-doped Mesoporous Silica Films for Rapid TNT Detection. Colloid Polym. Sci. 2007, 285, 721-728.

16. Tao, S.; Li, G.; Zhu, H., Metalloporphyrins as Sensing Elements for the Rapid Detection of Trace TNT Vapor. J. Mater. Chem. 2006, 16, 4521-4528.

17. Tao, S.; Shi, Z.; Li, G.; Li, P. Hierarchically Structured Nanocomposite Films as Highly Sensitive Chemosensory Materials for TNT Detection. Chem. Phys. Chem. 2006, 7, 1902-1905.

18. Johnson-White, B.; Zeinali, M.; Shaffer, K.M.; Patterson, J.; Charles, P.T.; Markowitz, M.A. Detection of Organics Using Porphyrin Embedded Nanoporous Organosilicas. Biosens. Bioelect. 2007, 22, 1154-1162.

19. Kosuge, K.; Murakami, T.; Kikukawa, N.; Takemori, M. Direct Synthesis of Porous Pure and Thiol-Functional Silica Spheres through the S+X-I+ Assembly Pathway. Chem. Mater. 2003, 15, 3184-3189.

20. Matsumoto, A.; Misran, H.; Tsutsumi, K. Adsorption Characteristics of Organosilica Based Mesoporous Materials. Langmuir 2004, 20, 7139-7145.

21. Palaniappan, A.; Su, X.; Tay, F.E.H. Functionalized Mesoporous Silica Films for Gas Sensing Applications. J. Electroceram. 2006, 16, 503-505.

22. Kresge, C.T.; Leonowicz, M.E.; Roth, W.J.; Vartuli, J.C.; Beck, J.S. Ordered Mesoporous Molecular Sieves Synthesized by a Liquid-crystal Template Mechanism. Nature 1992, 359, 710-712.

23. Burleigh, M.C.; Markowitz, M.A.; Wong, E.M.; Lin, J.S.; Gaber, B.P. Synthesis of Periodic Mesoporous Organosilicas with Block Copolymer Templates. Chem. Mater. 2001, 13, 4411-4412.

24. Goto, Y.; Inagaki, S. Synthesis of Large-pore Phenylene-bridged Mesoporous Organosilica Using Triblock Copolymer Surfactant. Chem. Commun. 2002, 20, 2410-2411.

25. Melde, B.J.; Johnson, B.J.; Dinderman, M.A.; Deschamps, J.R. Macroporous periodic mesoporous organosilicas with diethylbenzene bridging groups. Microp. Mesop. Mater. 2009, 130, 180-188.

26. Nakanishi, K. Pore Structure Control of Silica Gels Based on Phase Separation. J. Porous Mater. 1997, 4, 67-112. 
27. Nakanishi, K.; Kobayashi, Y.; Amatani, T.; Hirao, K.; Kodaira, T. Spontaneous Formation of Hierarchical Macro-Mesoporous Ethane-Silica Monolith. Chem. Mater. 2004, 16, 3652-3658.

28. Nakanishi, K.; Kanamori, K. Organic-Inorganic Hybrid Poly(silsesquioxane) Monoliths with Controlled Macro- and Mesopores. J. Mater. Chem. 2005, 15, 3776-3786.

29. Amatani, T.; Nakanishi, K.; Hirao, K.; Kodaira, T. Monolithic Periodic Mesoporous Silica with Well-Defined Macropores. Chem. Mater. 2005, 17, 2114-2119.

30. Nakanishi, K.; Amatani, T.; Yano, S.; Kodaira, T. Multiscale Templating of Siloxane Gels via Polymerization-Induced Phase Separation. Chem. Mater. 2008, 20, 1108-1115.

31. Brandhuber, D.; Peterlik, H.; Huesing, N. Facile Self-Assembly Processes to Phenylene-Bridged Silica Monoliths with Four Levels of Hierarchy. Small 2006, 2, 503-506.

32. Zhong, H.; Zhu, G.; Yang, J.; Wang, P.; Yang, Q. Periodic Mesoporous Hybrid Monolith with Hierarchical Macro-Mesopores. Micropor. Mesopor. Mater. 2007, 100, 259-267.

33. Jayasundera, S.; Burleigh, M.C.; Zeinali, M.; Spector, M.S.; Miller, J.B.; Yan, W.; Dai, S.; Markowitz, M.A. Organosilica Copolymers for the Adsorption and Separation of Multiple Pollutants. J. Phys. Chem. B 2005, 109, 9198-9201.

34. Loy, D.A.; Shea, K.J. Bridged Polysilsesquioxanes. Highly Porous Hybrid Organic-Inorganic Materials. Chem. Rev. 1995, 95, 1431-1442.

35. Johnson, B.J.; Melde, B.J.; Charles, P.T.; Cardona, D.C.; Dinderman, M.A.; Malanoski, A.P.; Qadri, S.B. Imprinted Nanoporous Organosilicas for Selective Adsorption of Nitroenergetic Targets. Langmuir 2008, 24, 9024-9029.

36. Johnson-White, B.; Zeinali, M.; Malanoski, A.P.; Dinderman, M. Sunlight Catalyzed Conversion of Cyclic Organics with Novel Mesoporous Organosilicas. Catalysis Comm. 2007, 8, 1052-1056.

37. White, B.J.; Harmon, H.J. Optical Determination of Bacterial Exosporium Sugars Using Immobilized Porphyrins. IEEE Sensors J. 2005, 5, 726-732.

38. Johnson, B.J.; Melde, B.J.; Charles, P.T.; Malanoski, A.P. Porphyrin-embedded organosilicas for detection and decontamination; In Proceedings of 2009 SPIE International Defense, Security and Sensing Symposium, Orlando, FL, USA, April 2009; Kumar, V., Prabhakar, S., Ross, A.A., Halvorson, H.S., Southern, S.O., Eds.; SPIE: Orlando, FL, USA, 2009.

39. Kim, H.J.; Guiochon, G. Comparison of the Thermodynamic Properties of Particulate and Monolithic Columns of Molecularly Imprinted Copolymers. Anal. Chem. 2005, 77, 93-102.

40. Umpleby, R.J.; Baxter, S.C.; Bode, M.; Berch, J.K.; Shah, R.N.; Shimizu, K.D. Application of the Freundlich Adsorption Isotherm in the Characterization of Molecularly Imprinted Polymers. Anal. Chim. Acta 2001, 435, 35-42.

41. Nozawa, A.; Ohnuma, T. Improved High-performance Liquid-chromatographic Analysis of Ehtylene-oxide Condensates by Their Esterification with 2,5-Dinitrobenzoyl Chloride. J. Chromatogr. 1980, 187, 261-263.

42. Sun, C.; Baird, M.; Anderson, H.A.; Brydon, D.L. Separation and Determination of Oligomers and Homologues of Aliphatic Alcohol Ethoxylates in Textile Lubricants and Lubricant Emulsion by High-performance Liquid Chromatography. J. Chromatogr. 1997, 771, 145-154.

43. Sun, C.; Baird, M.; Simpson, J. Determination of Poly(ethylene glycol)s by Both Normal-phase and Reversed-phase Modes of High-performance Liquid. J. Chromatogr. 1998, 800, 231-238. 
44. Gebreegzi, Y.T.; Foster, G.D.; Khan, S.U. Simulltaneous Determination of Carbaryl, Malathion, Fenitrothion, and Diazinon Residues in Sesame Seeds (Seasmum indicum L). J. Agric. Food Chem. 2000, 48, 5165-5168.

45. Tscharntke, T.; Hochberg, M.E.; Rand, T.A.; Resh, V.H.; Krauss, J. Author Sequence and Credit for Contributions in Multiauthored Publications. PLoS Biol. 2007, 5, e18.

(C) 2010 by the authors; licensee Molecular Diversity Preservation International, Basel, Switzerland. This article is an open-access article distributed under the terms and conditions of the Creative Commons Attribution license (http://creativecommons.org/licenses/by/3.0/). 